\title{
Antitumor effect of metformin in esophageal cancer: In vitro study
}

\author{
MITSUYOSHI KOBAYASHI $^{1}$, KIYOHITO KATO ${ }^{1}$, HISAKAZU IWAMA ${ }^{2}$, SHINTARO FUJIHARA $^{1}$, \\ NORIKO NISHIYAMA ${ }^{1}$, SHIMA MIMURA ${ }^{1}$, YUKA TOYOTA ${ }^{1}$, TAKAKO NOMURA ${ }^{1}$, KEI NOMURA ${ }^{1}$, \\ JOJI TANI ${ }^{1}$, HISAAKI MIYOSHI ${ }^{1}$, HIDEKI KOBARA ${ }^{1}$, HIROHITO MORI ${ }^{1}$, \\ KOJI MURAO ${ }^{3}$ and TSUTOMU MASAKI ${ }^{1}$ \\ ${ }^{1}$ Department of Gastroenterology and Neurology, ${ }^{2}$ Life Science Research Center, ${ }^{3}$ Department of Laboratory Medicine, \\ Faculty of Medicine, Kagawa University, Kagawa 761-0793, Japan
}

Received September 11, 2012; Accepted October 22, 2012

DOI: 10.3892/ijo.2012.1722

\begin{abstract}
Recent studies suggest that metformin, which is a member of the biguanide family and commonly used as an oral anti-hyperglycemic agent, may reduce cancer risk and improve prognosis of numerous types of cancer. However, the mechanisms underlying the antitumor effect of metformin on esophageal cancer remain unknown. The goal of the present study was to evaluate the effects of metformin on the proliferation of human ESCC in vitro, and to study changes in the expression profile of microRNAs (miRNAs), since miRNAs have previously been associated with the antitumor effects of metformin in other human cancers. The human ESCC cell lines T.T, KYSE30 and KYSE70 were used to study the effects of metformin on human ESCC in vitro. In addition, we used miRNA array tips to explore the differences between miRNAs in KYSE30 cells with and without metformin treatment. Metformin inhibited the proliferation of T.T, KYSE30 and KYSE70 cells in vitro. Metformin blocked the cell cycle in G0/G1 in vitro. This blockade was accompanied by a strong decrease of G1 cyclins, especially cyclin D1, as well as decreases in cyclin-dependent kinase (Cdk)4, Cdk6 and phosphorylated retinoblastoma protein $(\mathrm{Rb})$. In addition, the expression of miRNAs was markedly altered with the treatment of metformin in vitro. Metformin inhibited the growth of three ESCC cell lines, and this inhibition may have involved reductions in cyclin D1, Cdk4 and Cdk6.
\end{abstract}

\section{Introduction}

Esophageal cancer is now the eighth most common cancer and the sixth-leading cause of cancer-related mortality worldwide.

Correspondence to: Dr Tsutomu Masaki, Department of Gastroenterology and Neurology, Faculty of Medicine, Kagawa University, 1750-1 Ikenobe, Miki-cho, Kita-gun, Kagawa 761-0793, Japan

E-mail: tmasaki@med.kagawa-u.ac.jp

Key words: esophageal squamous cell carcinoma, metformin, microRNA
The disease often remains undiagnosed until the late stages, and advanced esophageal cancer is associated with a poor outcome and is one of the most refractory of cancers. Apart from potentially curative surgery, chemotherapy and radiochemotherapy may be applied at advanced stages, but neither can cure the disease in such cases, and even after these treatments the prognosis remains poor (1). Thus, there is a strong demand for new curative approaches to advanced esophageal cancer.

Metformin is an oral biguanide drug introduced into clinical practice in the 1950s for the treatment of type 2 diabetes (2). It lowers hyperglycemia by inhibiting hepatic glucose production. Recently, another function of metformin was found. According to a large number of recent observational studies, diabetic patients treated with metformin show a reduced incidence of neoplastic disease. In addition, in numerous basic investigations, including our own, metformin inhibited the proliferation of various human cancer cell types, such as prostate (3), breast (4), colon $(5,6)$, glial $(3,5,7,8)$ and gastric cancer $(9)$. However, there have been no reports on the effects of metformin on esophageal cancers. In addition, the mechanism underlying the suppression of cancer growth by metformin remains relatively unknown. Here we studied whether metformin would be effective against ESCC, and also investigated the expression of cell cycle-related molecules and receptor tyrosine kinase, and the angiogenic profiles, in order to explore the mechanisms underlying the general antitumor effects of metformin. We also attempted to identify microRNAs (miRNAs) associated with the antitumor effects of metformin.

\section{Materials and methods}

Chemicals. Metformin (1,1-dimethylbiguanide) was purchased from Astellas Pharma (Tokyo, Japan). The Cell Counting Kit (CCK-8) was purchased from Dojindo Laboratories (Kumamoto, Japan) and all other chemicals were obtained from Sigma Chemical (Tokyo, Japan).

Antibodies. In this study, the antibodies used were as follows: anti- $\beta$-actin monoclonal antibody (A5441, used at 1:3,000; Sigma-Aldrich), cyclin D1 (RB-9041, used at 1:1,000; Thermo 
Fisher Scientific, Waltham, MA), cyclin E (used at 1:1,000; BD Biosciences, Franklin Lakes, NJ), Cdk6 (sc-177, used at 1:1,000; Santa Cruz Biotechnology, Santa Cruz, CA), Cdk4 (no. 2906, used at 1:1,000; Cell Signaling Technology, Danvers, MA), Cdk2 (sc-163, used at 1:2,000; Santa Cruz Biotechnology), and phosphorylated $\mathrm{Rb}(\mathrm{pRb})$ (no. 9309, used at 1:1,000; Cell Signaling Technology). Secondary horseradish peroxidaselinked anti-mouse and anti-rabbit IgG antibodies (used at 1:2,000; GE Healthcare, Buckinghamshire, UK) were also used.

Cell lines and culture. The human ESCC cell lines KYSE30, KYSE70 and T.T were obtained from the Japanese Cancer Research Resources Bank (Tokyo, Japan). KYSE30 and KYSE70 cells were grown in Ham's F12 (Wako, Osaka, Japan)/RPMI-1640 (Gibco Invitrogen, Carlsbad, CA) supplemented with $20 \%$ fetal bovine serum (533-69545; Wako), penicillin-streptomycin (100 mg/l; Invitrogen) in a humidified atmosphere of $5 \% \mathrm{CO}_{2}$ at $37^{\circ} \mathrm{C}$. T.T cells were grown in DMEM/Ham's F12 medium (Wako) with $10 \%$ fetal bovine serum, penicillin-streptomycin $(100 \mathrm{mg} / \mathrm{l})$ in a humidified atmosphere of $5 \% \mathrm{CO}_{2}$ at $37^{\circ} \mathrm{C}$.

Cell proliferation assay. Cell proliferation assays were performed using the CCK-8 according to the manufacturer's instructions. Each cell type $\left(1 \times 10^{4}\right)$ was seeded into a well of a 96-well plate and cultured in $100 \mu \mathrm{l}$ of each culture medium. After $24 \mathrm{~h}$, seeding cells were treated by addition of 1,5 or $10 \mathrm{mM}$ metformin into the culture medium or left untreated. At the indicated time points, the medium was exchanged for $110 \mu \mathrm{l}$ of each culture medium with CCK-8 reagent (10 $\mu$ l CCK-8 and $100 \mu \mathrm{l}$ each culture medium), and the cells were incubated for $2 \mathrm{~h}$. Absorbance was measured at a wavelength of $450 \mathrm{~nm}$ using an auto-microplate reader.

Preparation of cell lysate. The lysate was performed according to the methods described in our previous reports $(10,11)$. All steps were carried out at $4^{\circ} \mathrm{C}$. Protein concentrations were measured using a dye-binding protein assay based on the Bradford method (12).

Gel electrophoresis and western blot analysis. Sodium dodecyl sulfate-polyacrylamide gel electrophoresis (SDS-PAGE) was performed according to the method of Laemmli (13), and western blot analysis was performed as described by Towbin et al (14) using primary antibodies and HRP-conjugated secondary antibodies. Immunoreactive proteins were visualized with an enhanced chemiluminescence detection system (Perkin Elmer Co., Waltham, MA) on X-ray film.

Flow cytometry analysis. To evaluate the mechanism of growth inhibition by metformin, the cell cycle profile was analyzed after treatment with metformin. KYSE30 cells $\left(1.0 \times 10^{6}\right.$ cells in a 6-well plate dish) were treated with $10 \mathrm{mM}$ metformin or left untreated for 24-72 h. After treatment, the cells were harvested and fixed in $80 \%$ ethanol. The fixed cells were washed with PBS and then stored at $-20^{\circ} \mathrm{C}$ until flow cytometric analysis was performed. On the day of analysis, cells were washed and centrifuged using cold PBS, suspended in $100 \mu \mathrm{l}$ PBS and $10 \mu \mathrm{l}$ RNase A solution $(250 \mu \mathrm{g} / \mathrm{ml})$, and incubated for $30 \mathrm{~min}$ at $37^{\circ} \mathrm{C}$. Then, $110 \mu \mathrm{l}$ propidium iodide (PI) stain $(100 \mu \mathrm{g} / \mathrm{ml})$ was added to each tube, which was then incubated at $4^{\circ} \mathrm{C}$ for at least $30 \mathrm{~min}$ prior to analysis. Flow cytometric analysis was performed using a Cytomics FC 500 flow cytometer (Beckman Coulter, Brea, CA) equipped with an argon laser $(488 \mathrm{~nm})$. The percentages of cells in different phases of the cell cycle were analyzed by using FlowJo software (Tree Star, Ashland, OR). All experiments were performed in triplicate to assess for consistency of response.

Antibody arrays of phosphorylated receptor tyrosine kinase $(p-R T K)$. The RayBio ${ }^{\mathrm{TM}}$ Human Phospho Array Kit (catalog no. ARY 001) was purchased from RayBiotech Inc. (Norcross, GA). The assay for p-RTK array was performed according to the manufacturer's instructions. Briefly, p-RTK array membranes were blocked with 5\% BSA/TBS (0.01 M Tris-HCl, $\mathrm{pH}$ 7.6) for $1 \mathrm{~h}$. Membranes were then incubated with $2 \mathrm{ml}$ of lysate prepared from cell lines or tumorous tissues after normalization with equal amounts of protein. After extensive washing with TBS including $0.1 \% \mathrm{v} / \mathrm{v}$ Tween-20 ( 3 washings for $10 \mathrm{~min}$ each) and with TBS alone (2 washings for $10 \mathrm{~min}$ each) to remove unbound materials, the membranes were incubated with antiphospho-tyrosine-HRP antibody for $2 \mathrm{~h}$ at room temperature. The unbound HRP antibody was washed out with TBS including $0.1 \%$ Tween-20. Finally, each array membrane was exposed to $\mathrm{X}$-ray film using a chemiluminescence detection system (Perkin Elmer Co.). The density of the immunoreactive band obtained on the p-RTK array was analyzed by densitometric scanning (Tlc scanner; Shimizu Co. Ltd., Kyoto, Japan).

Angiogenic profile analysis using an antibody array. The RayBio $^{\text {TM }}$ Human Angiogenesis Antibody Array 1 kit (catalog no. AAH-ANG-1) was purchased from RayBiotech Inc. The assay for array was performed according to the manufacturer's instructions. Briefly, the angiogenesis antibody membranes were blocked with blocking buffer for $30 \mathrm{~min}$. The membranes were then incubated with $1 \mathrm{ml}$ of lysate prepared from cell lines after normalization with equal amounts of protein. After extensive washing with TBS including $0.1 \% \mathrm{v} / \mathrm{v}$ Tween-20, 3 times for $10 \mathrm{~min}$, and TBS alone, 2 times for $10 \mathrm{~min}$, to remove unbound materials, the membranes were then incubated with anti-phospho-tyrosine-HRP antibody for $2 \mathrm{~h}$ at room temperature. The unbound HRP antibody was washed out with TBS including $0.1 \%$ Tween-20. Finally, each array membrane was exposed to X-ray film using a chemiluminescence detection system (Perkin Elmer Co.). The density of the immunoreactive band obtained on this array was analyzed by densitometric scanning (Tlc scanner; Shimizu Co. Ltd.).

Analysis of the miRNA array. The samples of cancer cell lines were processed for total-RNA extraction with a miRNeasy mini kit (Qiagen, Hilden, Germany) according to the manufacturer's instructions. RNA samples typically showed A260/280 ratios of between 1.9 and 2.1, as determined using an Agilent 2100 Bioanalyzer (Agilent Technologies, Santa Clara, CA).

After RNA measurement with an RNA 6000 Nano kit (Agilent Technologies), the samples were labeled using a miRCURY Hy3/Hy5 Power labeling kit and were hybridized on a human miRNA Oligo chip (v.14.0; Toray Industries, Tokyo, Japan). Scanning was performed with a 3D-Gene Scanner 3000 (Toray Industries). 3D-Gene extraction version 1.2 software (Toray Industries) was used to read the raw intensity of the image. To determine the change in miRNA expression 
T.T

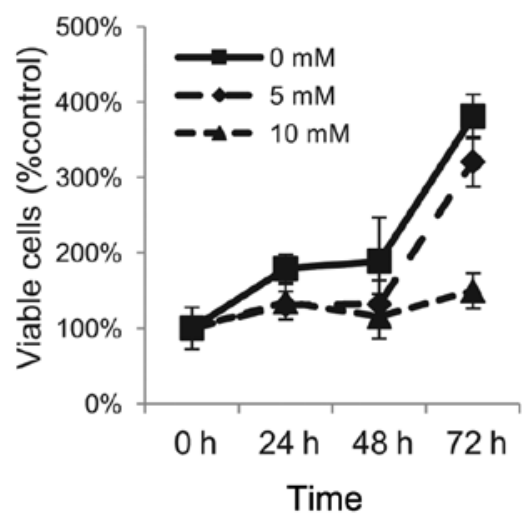

KYSE30

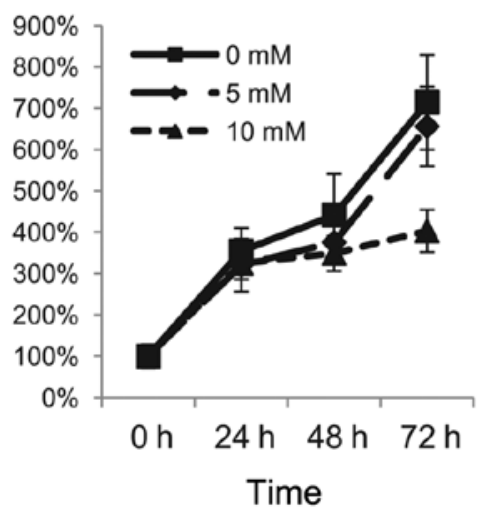

KYSE70

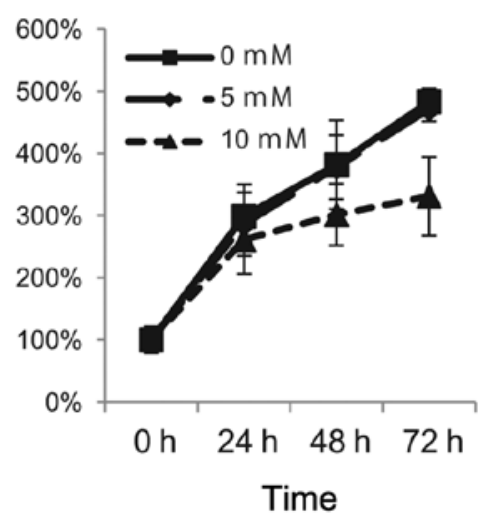

Figure 1. T.T, KYSE30 and KYSE70 cells were seeded at 10,000 cells per well in a 96-well plates and the agents were added at time 0 h. A cell counting kit assay was conducted daily from time 0 to $72 \mathrm{~h}$. The mean cell number from three independent cultures is shown. Error bars represent the standard deviation. In T.T and KYSE30 cells, the conditions at 48 and $72 \mathrm{~h}$ in the cells treated with metformin were significantly different compared with those in the control $(0 \mathrm{mM})$, at $\mathrm{p}<0.05$. In KYSE70 cells, the conditions at 48 and $72 \mathrm{~h}$ in the group treated with $10 \mathrm{mM}$ metformin were significantly different compared with those in the control $(0 \mathrm{mM})$ and $5 \mathrm{mM}$ metformin-treated group, at $\mathrm{p}<0.05$.

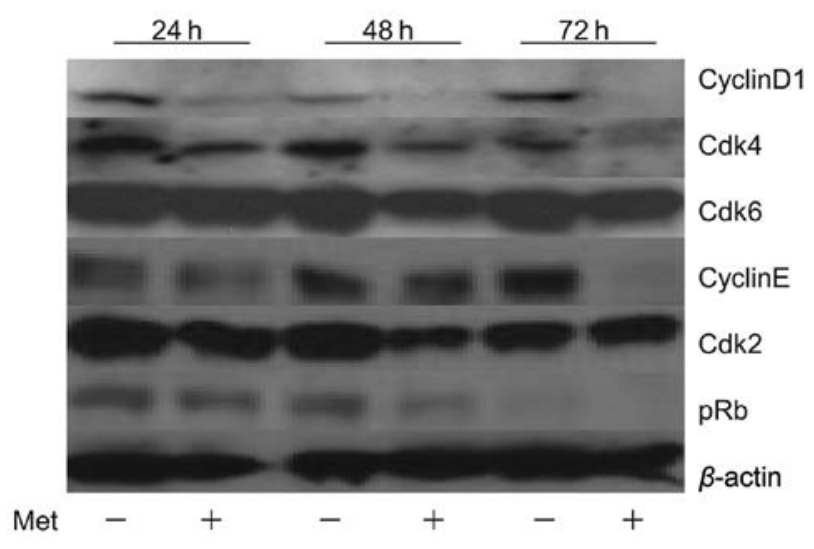

Figure 2. Metformin blocks the cell cycle in G0/G1 and affects the expression levels of the various cell cycle-regulatory proteins in KYSE30 cells. Western blot analysis of cyclin D1, Cdk4, Cdk6, cyclin E, Cdk2, and pRb in KYSE30 cells at 25,48 and $72 \mathrm{~h}$ after the addition of $10 \mathrm{mM}$ metformin for the indicated time. $\beta$-actin was used as a loading control.

between metformin-treated and control samples, the raw data were analyzed via GeneSpringGX v10.0 (Agilent Technologies). Samples were first normalized relative to 28sRNA and baselinecorrected to the median of all samples.

Replicate data were consolidated into two groups: those from metformin-treated cells and those from control cells, and were organized by using the hierarchical clustering and analysis of variance (ANOVA) functions in the GeneSpring software. Hierarchical clustering was done by using the clustering function (condition tree) and Euclidean correlation as a distance metric. Two-way ANOVA analysis and asymptotic p-value computation without any error correction on the samples were performed to search for the miRNAs that varied most prominently across the different groups. The p-value cutoff was set to 0.05 . Only changes $>50 \%$ in at least one of the time points for each sample were considered significant. All the analyzed data were scaled by global normalization. The statistical significance of differentially expressed miRNAs was analyzed by Student's t-test.
Statistical analysis. All analyses were performed using the computer-assisted JMP8.0 (SAS Institute, Cary, NC). Paired analysis between the groups was performed using Student's t-test. A p-value of 0.05 was considered to indicate a significant difference between groups.

\section{Results}

Effect of metformin on the proliferation of human ESCC cells. To evaluate the effect of the growth activity of metformin on human ESCC cells in vitro, we examined metformin's effect on the proliferation of three esophageal squamous cell carcinoma cell lines: T.T, KYSE30 and KYSE70. To discern the direct relationship between the decrease in cell viability and the inhibition of cell proliferation, we followed the course of proliferation over 3 days after the addition of metformin. Cells were grown in culture medium and treated with 5 or $10 \mathrm{mM}$ metformin or, as a control, without metformin. As shown in Fig. 1, metformin led to a dose-dependent and strong inhibition of cell proliferation in the ESCC cell lines T.T and KYSE30. In KYSE70 cells, although $5 \mathrm{mM}$ metformin did not effect the proliferation of cancer cells, treatment with $10 \mathrm{mM}$ metformin inhibited the proliferation of cells. These results suggest that metformin inhibits ESCC proliferation.

Effects of metformin on cell cycle regulatory proteins in KYSE30. To study whether or not metformin affects the cell cycle in KYSE30 cells, western blot analysis was used to examine the expression of various cell cycle-related molecules in KYSE30 with and without metformin treatment. Cells were treated with $10 \mathrm{mM}$ metformin or left untreated for 24-72 h. The most remarkable change was the loss of cyclin D1, a key protein implicated in the transition of the G0/G1 phase. In short, the cyclin D1 level was already reduced at $24 \mathrm{~h}$ after the addition of metformin and was no longer detectable at 48 and $72 \mathrm{~h}$ (Fig. 2). We then studied the expression of other cell cycle-related proteins (Cdk4, Cdk6, cyclin E and Cdk2) implicated in the G0/G1 transition. Cdk4 and Cdk6, the catalytic 
A
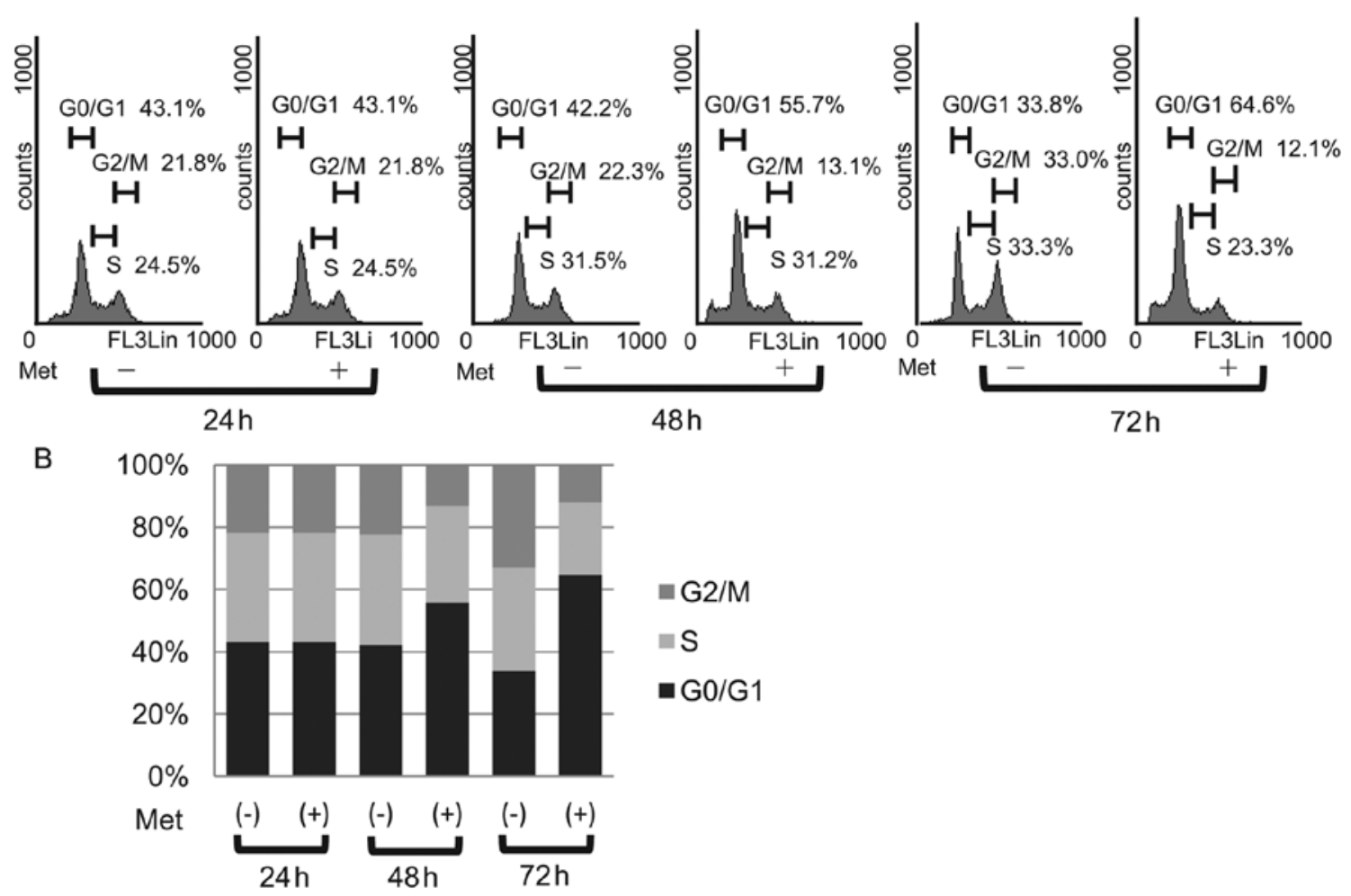

Figure 3. Flow cytometry analysis of proliferating KYSE30 cells at 24,48 and $72 \mathrm{~h}$ after the addition of $10 \mathrm{mM}$ metformin. Results are representative of three independent experiments. Note that cells after 48 and 72-h treatment with $10 \mathrm{mM}$ metformin are inhibited cell cycle progression from G0-G1 into S-phase.

subunit of cyclin D1, was slightly decreased at 48 and $72 \mathrm{~h}$ after the addition of metformin. Cyclin E was decreased at $72 \mathrm{~h}$ after the addition of metformin. The catalytic subunit of cyclin E, Cdk2, was also slightly decreased at 48 and $72 \mathrm{~h}$ after the addition of metformin. The level of $\mathrm{pRb}$ also decreased progressively in metformin-treated cells. These events were also detected in the two other cancer cell lines, i.e., T.T and KYSE70 (data not shown). The amount of $\beta$-actin (an internal control for protein loading) was almost the same in each lane in sodium dodecyl sulfate polyacrylamide gel electrophoresis (Fig. 2).

To further investigate the inhibition of KYSE30 cell proliferation in the presence of metformin, the cell cycle progression was examined by flow cytometry. We treated proliferating KYSE30 cells with $10 \mathrm{mM}$ metformin for different durations. After the addition of $10 \mathrm{mM}$ metformin, an increasing number of cells started to accumulate in G0/G1, 55.7\% after $48 \mathrm{~h}$ and $64.6 \%$ by $72 \mathrm{~h}$ (Fig. 3A). In parallel, we observed reductions in the percentage of cells in the $S$ phase and G2/M phase (Fig. 3B). These data suggest that metformin inhibits the cell cycle progression from G0/G1 into $S$ phase, resulting in $\mathrm{G} 1$ cell cycle arrest.

Differences in phosphorylated-receptor tyrosine kinases p-(RTKs) in KYSE30 cells with or without metformin treatment in vitro. Having established the antitumor effects of metformin in the ESCC cell lines, we next used a phosphorylated-RTK array system to identify the 'key' RTKs in terms of these antitumor effects. By using an antibody array (Fig. 4A), we simultaneously screened the expression of 42 different RTKs in KYSE30 cells with or without metformin. The results showed that the expression of phosphorylated-epidermal growth factor (p-EGFR) (Fig. 4B) was reduced by the treatment of metformin.

The density of the p-EGFR obtained from the membrane array was analyzed by means of a Kodak Image Station (Eastman Kodak, Rochester, NY). The densitometric ratio of the p-EGFR spots of the metformin-treated cell lines to the p-EGFR spots of the cell lines not treated with metformin was reduced to $58.4 \%$ (Fig. $4 \mathrm{C}$ ).

Differences in angiogenesis-related protein expression in KYSE30 cells with or without metformin treatment in vitro. We used an angiogenesis antibody array system to identify the 'key' angiogenesis-related protein in terms of the antitumor effect of metformin.

By using the antibody array (Fig. 5A), we simultaneously screened the expression of 20 different angiogenesis antibodies in KYSE30 cells with or without metformin. The expression of interleukin-8 (IL-8), tissue inhibitor of metalloproteinases-1 (TIMP-1) and basic fibroblast growth factor (bFGF) (Fig. 5B) were reduced by the treatment with metformin as detected by the protein array.

The density of the IL-8, TIMP-1 and bFGF obtained from the membrane array was analyzed using the Kodak Image Station (Eastman Kodak). The densitometric ratio of the TIMP-1, IL-8 and bFGF spots from metformin-treated cells to those of cells not treated with metformin were $15.9,37.4$ and $23.3 \%$, respectively (Fig. 5C). 
A

\begin{tabular}{|c|c|c|c|c|c|c|c|c|c|c|c|}
\hline $\begin{array}{c}\text { PY- } \\
\text { control }\end{array}$ & & & & & & & & & & & $\begin{array}{c}\text { PY- } \\
\text { control }\end{array}$ \\
\hline EGFR & ErbB2 & ErbB3 & ErbB4 & FGFR1 & FGFR2 $a$ & FGFR3 & FGFR4 & InsulinR & IGF-1R & Axl & Dtk \\
\hline Mer & HGFR & MSPR & PDGFR $a$ & PDGFR $\beta$ & SCFR & Flt-3 & M-CSFR & c-Ret & ROR1 & ROR2 & Tie-1 \\
\hline Tie-2 & TrkA & TrkB & TrkC & VEGFR1 & VEGFR2 & VEGFR3 & MuSK & EphA1 & EphA2 & EphA3 & EphA4 \\
\hline EphA6 & EphA7 & EphB1 & EphB2 & EphB4 & EphB6 & $\begin{array}{c}\text { Mouse } \\
\text { IgG1 }\end{array}$ & $\begin{array}{l}\text { Mouse } \\
\text { lgG2A }\end{array}$ & $\begin{array}{l}\text { Mouse } \\
\text { lgG2B }\end{array}$ & $\begin{array}{c}\text { Goat } \\
\text { lgG }\end{array}$ & PBS & \\
\hline $\begin{array}{l}\text { PY- } \\
\text { control }\end{array}$ & & & & & & & & & & & $\begin{array}{l}\text { PY- } \\
\text { control }\end{array}$ \\
\hline
\end{tabular}

PY-control: Phospho tyrosine Positive Control

B

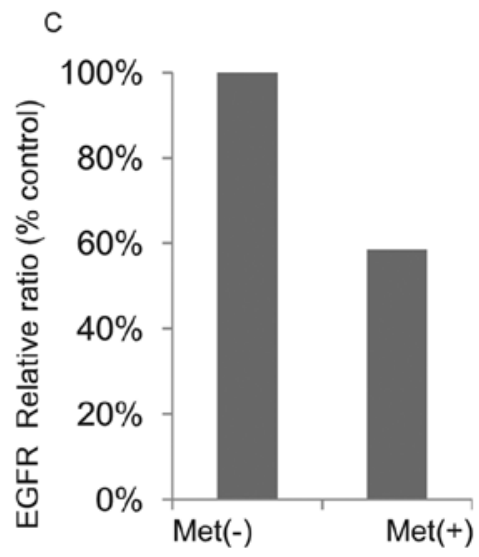

Figure 4. (A) Template showing the location of tyrosine kinase antibody spotted onto the Ray Bio Human phospho array kit. (B) Representative expression of various phosphorylated tyrosine kinases receptor in KYSE30 cells treated with or without metformin. The reduced expression of p-EGFR was detected in KYSE30 cells treated with metformin. (C) The densitometric ratio of the p-EGFR spots of metformin-treated KYSE30 cells to non-treated cells was 58.4\%.

A

\begin{tabular}{|c|c|c|c|c|c|c|c|}
\hline POS & POS & NEG & NEG & Angiogenin & EGF & ENA-78 & bFGF \\
\hline POS & POS & NEG & NEG & Angiogenin & EGF & ENA-78 & bFGF \\
\hline GRO & IFN- $\gamma$ & IGF-I & IL-6 & IL-8 & LEPTIN & MCP-1 & PDGF-BB \\
\hline GRO & IFN- $\gamma$ & IGF-I & IL-6 & IL-8 & LEPTIN & MCP-1 & PDGF-BB \\
\hline PIGF & RANTES & TGF- $\beta 1$ & TIMP-1 & TIMP-2 & $\begin{array}{c}\text { Thrombo } \\
\text { protein }\end{array}$ & VEGF & VEGF-D \\
\hline PIGF & RANTES & TGF- $\beta 1$ & TIMP1 & TIMP-2 & $\begin{array}{c}\text { Thrombo } \\
\text { protein }\end{array}$ & VEGF & VEGF-D \\
\hline BLANK & BLANK & BLANK & BLANK & BLANK & BLANK & Neg & POS \\
\hline BLANK & BLANK & BLANK & BLANK & BLANK & BLANK & Neg & POS \\
\hline
\end{tabular}

B

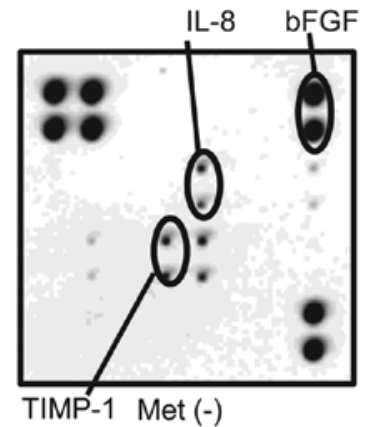

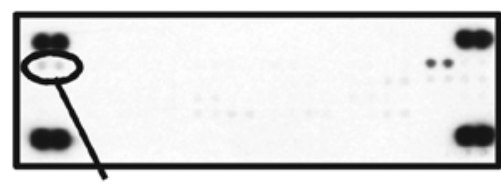

EGFR Met (+)
C

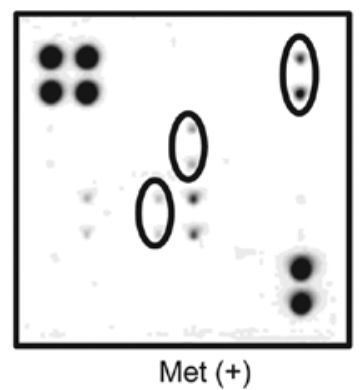

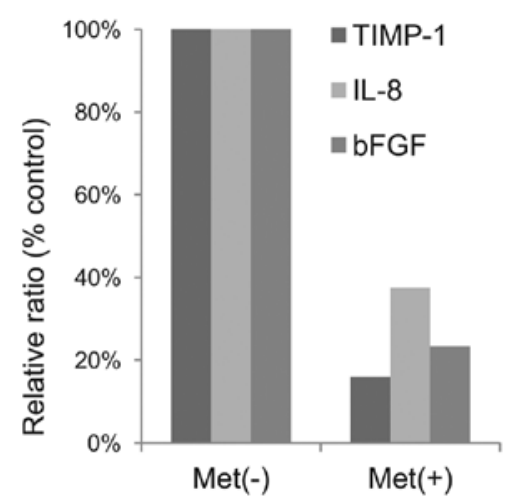

Figure 5. (A) Template showing the location of antibodies for angiogenesis-related protein spotted onto the Ray Bio Human Cytokine antibody array kit. (B) Representative expression of various antibodies for angiogenesis-related protein in KYSE30 cells with or without metformin treated. The reduced expression of TIMP-1, IL-8 and bFGF (black circle) were detected in cells treated with metformin. (C) The densitometric ratio of the TIMP-1, IL-8 and bFGF spots of metformin-treated KYSE30 cells to non-treated cells was $15.9,37.4$ and $23.3 \%$, respectively. 


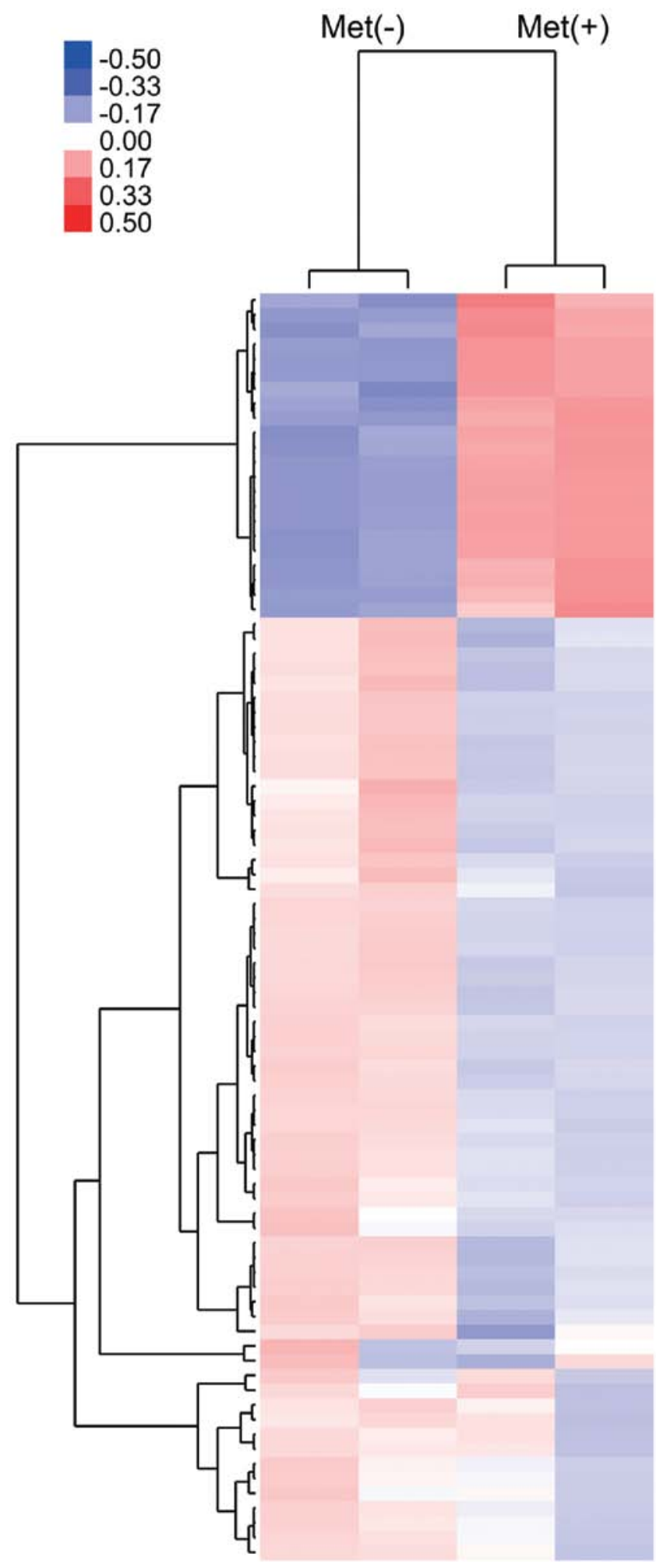

Figure 6. Hierarchical clustering of KYSE30 cells with metformin and without metformin (Met). KYSE30 cells were clustered according to the expression profiles of 62 miRNAs that were differentially expressed between KYSE30 cells with and without metformin treatment. The analyzed samples are shown in the columns and the miRNAs are presented in rows. The miRNA clustering tree is shown on the left and the sample-clustering tree appears at the top. The color scale shown at the top illustrates the relative expression level of miRNAs; red represents a high expression level, and blue represents a low expression level.

Differences in miRNA in KYSE30 cells with or without metformin treatment in vitro. Using a custom microarray plat- form, we analyzed the expression levels of 985 human miRNA probes in KYSE30 cells with or without metformin treatment in vitro. As shown in Fig. 6 and Table I, when the expression of miRNAs was studied in KYSE30 cells treated with $10 \mathrm{mM}$ metformin and without metformin in vitro, 17 miRNAs were significantly upregulated (Fig. 6 and Table I) in KYSE30 cells after $72 \mathrm{~h}$ of metformin treatment, while 45 miRNAs were downregulated (Fig. 6 and Table I) of the 985 miRNAs.

Unsupervised hierarchical clustering analysis, using Pearson's correlation, showed that KYSE30 cells treated with metformin clustered together and separately from the untreated cells (Fig. 6).

\section{Discussion}

Recent studies from our group and those of other authors have suggested that metformin is able to inhibit proliferation in various cancer cell lines, such as breast cancer (15), glial cancer (7) and prostate cancer (3) and gastric cancer (9). However, it has remained uncertain whether metformin would exert antitumor effects against ESCC. In the present study, we have shown that metformin is indeed a very potent inhibitor of human ESCC cell growth via G1 arrest of the cell cycle in vitro. In addition, the expression of miRNAs was markedly altered with the treatment of metformin in vitro.

Specific cyclin/cyclin-dependent kinase (Cdk) complexes are activated at different intervals during the cell cycle. Complexes of Cdk4 and Cdk6 with cyclin D1 are required for G1 phase progression, whereas complexes of $\mathrm{Cdk} 2$ with cyclin $\mathrm{E}$ are required for the G1/S transition (16).

In previous reports, including our own, downregulation of cyclin D1 in response to metformin has been demonstrated in various cancer cell lines, such as colon cancer (17), breast cancer (17), prostate cancer (3) and gastric cancer (9). However, the antitumor effects of metformin on catalytic subunits of cyclin D1, Cdk4 and Cdk6, remain unknown. In the present study, the major cell cycle regulators (cyclin D1, Cdk4, Cdk6, cyclin $\mathrm{E}, \mathrm{Cdk} 2$, phosphorylated $\mathrm{Rb}$ ) could be intracellular targets of the metformin-mediated anti-proliferative effect in human ESCC in vitro. In addition, flow cytometry demonstrated that metformin arrested ESCC cells at the G0/G1 phase in vitro. These data suggest that the antitumor effect of metformin for various cancers, including ESCC, may be related to the reduction of various cell cycle-related proteins, especially cyclin D1.

Metformin leads to changes in various protein phosphorylations. To date, changes in the phosphorylation of various molecules, such as, Akt, $\beta$-catenin, CREB, Chk2 (18) and c-Src (19) has been detected in cell lines treated with metformin. We also detected a reduction of p-EGFR in ESCC by metformin treatment using a protein array. These data suggest that the expression of p-EGFR is reduced with the treatment of metformin in ESCC. Some studies have also reported that metformin reduces the expression of p-EGFR and p-IGF-1R in breast (19) and pancreas cancer (20). Collectively, these results suggest that metformin might reduce the expression of p-EGFR and p-IGF in many cancer types, including ESCC. Therefore, the aberrant EGFR activation (enhanced p-EGFR) may lead to carcinogenesis (21). Our current data, together with those of the previous reports, indicate that the blocking of the cell cycle in G0/G1 may be due to the inhibition of EGFR activation (22). 
Table I. Statistical results and chromosomal locations of miRNAs in KYSE30 cells treated with metformin, compared with non-treated cells.

Fold (treated/non-treated)

\begin{tabular}{|c|c|c|c|c|c|c|c|}
\hline \multirow[b]{2}{*}{$\begin{array}{l}\text { Upregulated } \\
\text { miRNA }\end{array}$} & \multicolumn{3}{|c|}{ Fold (treated/non-treated) } & \multicolumn{4}{|c|}{ Fold (treated/non-treated) } \\
\hline & Mean \pm SD & P-value & $\begin{array}{l}\text { Chromosomal } \\
\text { localization }\end{array}$ & $\begin{array}{c}\text { Downregulated } \\
\text { miRNA }\end{array}$ & Mean \pm SD & P-value & $\begin{array}{c}\text { Chromosomal } \\
\text { localization }\end{array}$ \\
\hline hsa-miR-1246 & $2.16 \pm 0.115$ & 0.011827 & $2 \mathrm{q} 31.1$ & hsa-miR-22 & $0.75 \pm 0.005$ & 0.00571 & $17 \mathrm{p} 13.3$ \\
\hline hsa-miR-638 & $1.88 \pm 0.021$ & 0.01019 & $19 \mathrm{p} 13.2$ & hsa-miR-125a-3p & $0.77 \pm 0.006$ & 0.006262 & $19 q 13.41$ \\
\hline hsa-miR-149* & $1.84 \pm 0.086$ & 0.024371 & $2 q 37.3$ & hsa-miR-30e & $0.8 \pm 0.012$ & 0.011198 & $1 \mathrm{p} 34.2$ \\
\hline hsa-miR-663 & $1.68 \pm 0.051$ & 0.003587 & 20p11.1 & hsa-miR-31 & $0.82 \pm 0.008$ & 0.001852 & $9 q 21.3$ \\
\hline hsa-miR-1908 & $1.61 \pm 0.08$ & 0.018783 & $11 \mathrm{q} 12.2$ & hsa-miR-19a & $0.83 \pm 0.028$ & 0.006905 & $13 q 31.3$ \\
\hline hsa-miR-1268 & $1.6 \pm 0.005$ & 0.011672 & $15 q 11.2$ & hsa-miR-1260 & $0.85 \pm 0.003$ & 0.00294 & $14 q 24.3$ \\
\hline hsa-miR-3196 & $1.55 \pm 0.056$ & 0.024353 & $20 q 13.33$ & hsa-miR-301a & $0.85 \pm 0.003$ & 0.003951 & $17 q 22$ \\
\hline hsa-miR-2861 & $1.53 \pm 0.056$ & 0.02555 & $9 q 34.11$ & hsa-let-7f & $0.87 \pm 0.005$ & $1.22 \mathrm{E}-06$ & $9 q 22.32$ \\
\hline hsa-miR-3665 & $1.43 \pm 0.031$ & 0.018788 & $13 q 22.3$ & hsa-let-7c & $0.87 \pm 0.006$ & 0.002223 & $21 \mathrm{q} 21.1$ \\
\hline hsa-miR-3656 & $1.42 \pm 0.021$ & 0.020642 & $11 \mathrm{q} 23.3$ & hsa-let-7d & $0.87 \pm 0.009$ & 0.003382 & $9 q 22.32$ \\
\hline hsa-miR-762 & $1.42 \pm 0.052$ & 0.03006 & $16 \mathrm{p} 11.2$ & hsa-miR-19b & $0.88 \pm 0.006$ & 0.003734 & $13 q 31.3$ \\
\hline hsa-miR-3621 & $1.39 \pm 0.079$ & 0.047853 & $9 q 34.3$ & hsa-miR-17 & $0.88 \pm 0.007$ & 0.005864 & $13 \mathrm{q} 31.3$ \\
\hline hsa-miR-3648 & $1.37 \pm 0.073$ & 0.049042 & $21 \mathrm{p} 11.2$ & hsa-miR-221 & $0.88 \pm 0.003$ & 0.011279 & $\mathrm{Xq} 11.3$ \\
\hline hsa-miR-664 & $1.35 \pm 0.027$ & 0.017668 & $1 q 41$ & hsa-miR-20a & $0.88 \pm 0.011$ & 0.012623 & $13 \mathrm{q} 31.3$ \\
\hline hsa-miR-4284 & $1.18 \pm 0.012$ & 0.013386 & $7 q 11.23$ & hsa-miR-4286 & $0.89 \pm 0.006$ & 0.009008 & $8 \mathrm{p} 23.1$ \\
\hline hsa-miR-3175 & $1.16 \pm 0.039$ & 0.048742 & $15 q 26.1$ & hsa-miR-23b & $0.91 \pm 0.003$ & 0.000424 & $9 q 22.32$ \\
\hline \multirow[t]{29}{*}{ hsa-miR-3651 } & $1.12 \pm 0.004$ & 0.012559 & $9 q 22.31$ & hsa-miR-26b & $0.91 \pm 0.001$ & 0.005239 & $2 q 35$ \\
\hline & & & & hsa-let-7a & $0.86 \pm 0.003$ & 0.013342 & $9 q 22.32$ \\
\hline & & & & hsa-miR-141 & $0.91 \pm 0.007$ & 0.013575 & $12 \mathrm{p} 13.31$ \\
\hline & & & & hsa-miR-30a & $0.91 \pm 0.008$ & 0.013823 & $6 q 13$ \\
\hline & & & & hsa-miR-151-5p & $0.79 \pm 0.024$ & 0.017194 & $8 \mathrm{q} 24.3$ \\
\hline & & & & hsa-miR-103 & $0.88 \pm 0.013$ & 0.019115 & $5 q 34$ \\
\hline & & & & hsa-miR-200a & $0.91 \pm 0.009$ & 0.020473 & $1 \mathrm{p} 36.33$ \\
\hline & & & & hsa-miR-93 & $0.87 \pm 0.016$ & 0.020961 & $7 q 22.1$ \\
\hline & & & & hsa-miR-1260b & $0.91 \pm 0.009$ & 0.022633 & $11 q 21$ \\
\hline & & & & hsa-miR-1274b & $0.88 \pm 0.014$ & 0.024406 & \\
\hline & & & & hsa-miR-106a & $0.89 \pm 0.016$ & 0.024855 & $\mathrm{Xq} 26.2$ \\
\hline & & & & hsa-miR-16 & $0.88 \pm 0.008$ & 0.026064 & $13 q 14.2$ \\
\hline & & & & hsa-miR-1280 & $0.91 \pm 0.011$ & 0.026495 & $3 q 21.3$ \\
\hline & & & & hsa-miR-15b & $0.88 \pm 0.016$ & 0.027129 & $3 q 25.33$ \\
\hline & & & & hsa-miR-18a & $0.85 \pm 0.012$ & 0.027439 & $13 q 31.3$ \\
\hline & & & & hsa-miR-15a & $0.82 \pm 0.022$ & 0.027525 & $13 q 14.2$ \\
\hline & & & & hsa-miR-200c & $0.9 \pm 0.014$ & 0.027716 & $12 \mathrm{p} 13.31$ \\
\hline & & & & hsa-miR-107 & $0.88 \pm 0.018$ & 0.028234 & $10 q 23.31$ \\
\hline & & & & hsa-miR-200b & $0.94 \pm 0.009$ & 0.028265 & $1 \mathrm{p} 36.33$ \\
\hline & & & & hsa-miR-92a & $0.76 \pm 0.038$ & 0.02887 & $13 q 31.3$ \\
\hline & & & & hsa-miR-7 & $0.71 \pm 0.025$ & 0.031884 & $9 q 21.32$ \\
\hline & & & & hsa-miR-29a & $0.88 \pm 0.02$ & 0.032697 & $7 q 32.3$ \\
\hline & & & & hsa-miR-24 & $0.96 \pm 0.005$ & 0.032934 & $9 q 22.32$ \\
\hline & & & & hsa-miR-1274a & $0.84 \pm 0.029$ & 0.038101 & \\
\hline & & & & hsa-miR-181a & $0.77 \pm 0.039$ & 0.039589 & 1q32.1 \\
\hline & & & & hsa-miR-720 & $0.85 \pm 0.027$ & 0.040428 & $3 q 23.1$ \\
\hline & & & & hsa-miR-26a & $0.86 \pm 0.021$ & 0.040936 & $3 \mathrm{p} 22.2$ \\
\hline & & & & hsa-miR-20b & $0.9 \pm 0.023$ & 0.046995 & $\mathrm{Xq} 26.2$ \\
\hline & & & & hsa-miR-191 & $0.89 \pm 0.021$ & 0.049584 & $3 \mathrm{p} 21.31$ \\
\hline
\end{tabular}

Fold (treated/non-treated) 
In the present study, metformin was found to reduce some angiogenesis-related proteins, such as interleukin-8 (IL-8), tissue inhibitor of metalloproteinases-1 (TIMP-1) and basic fibroblast growth factor (bFGF). TIMP-1 is not only related to angiogenesis, but also possesses the ability of cell growth promotion. In addition, a previous report has shown that the enhanced expressions of b-FGF and IL- 8 are associated with the development of advanced esophageal cancer (23). These data suggest that the antitumor effect of metformin may be due to the reduction of TIMP-1, IL-8 and b-FGF.

Using microRNA (miRNA) expression arrays, we have determined variations in miRNA profiles in ESCC cell lines in culture treated with metformin compared to those not treated with metformin. The cluster analysis clearly demonstrated that metformin treatment affects the expression of numerous miRNAs in cultured cells. In the analyses, we selected sets of miRNAs that altered their expression levels significantly with and without metformin treatment. We identified 62 miRNAs differentially expressed (17 upregulated and 45 downregulated) in cell culture. These data suggest that miRNAs may be meaningful candidates to gauge the effectiveness of metformin treatment and to provide clues to the molecular basis of the anticancer effects of metformin.

We found that the most changed miRNA in ESCC cells treated with metformin was miR-1246, which was upregulated 2.16-fold in cells treated with metformin, as compared with the control. Recently, Zhang et al (24) reported that miR-1246 is induced by p53 activation, and plays a role in the induction of apoptosis in cancer cells. In previous reports $(20,25)$, metformin was also demonstrated to possess antitumor effects through the induction of apoptosis in various cancer cells. In agreement with these studies, our data also suggest that miR-1246 may be associated with the antitumor effects of metformin in ESCC cells.

In conclusion, our results revealed that metformin inhibits human ESCC cell proliferation, possibly by suppressing cell cycle-related molecules via activation of EGFR, induction of TIMP1, IL-8 and alteration of miRNAs. Therefore, metformin may become a novel and effective therapeutic agent for the treatment and long-term management of ESCC providing additional benefits at low cost. Further studies are necessary, however, to resolve many remaining problems.

\section{References}

1. Sant M, Aareleid T, Berrino F, et al: EUROCARE-3: survival of cancer patients diagnosed 1990-94 - results and commentary. Ann Oncol 14 (Suppl 5): v61-v118, 2003.

2. Witters LA: The blooming of the French lilac. J Clin Invest 108: 1105-1107, 2001.

3. Ben Sahra I, Laurent K, Loubat A, et al: The antidiabetic drug metformin exerts an antitumoral effect in vitro and in vivo through a decrease of cyclin D1 level. Oncogene 27: 3576-3586, 2008.

4. Brown KA, Hunger NI, Docanto M and Simpson ER: Metformin inhibits aromatase expression in human breast adipose stromal cells via stimulation of AMP-activated protein kinase. Breast Cancer Res Treat 123: 591-596, 2010.
5. Zhou XZ, Xue YM, Zhu B and Sha JP: Effects of metformin on proliferation of human colon carcinoma cell line SW-480. Nan Fang Yi Ke Da Xue Xue Bao 30: 1935-1942, 2010 (In Chinese).

6. Hosono K, Endo H, Takahashi H, et al: Metformin suppresses azoxymethane-induced colorectal aberrant crypt foci by activating AMP-activated protein kinase. Mol Carcinog 49: 662-671, 2010.

7. Isakovic A, Harhaji L, Stevanovic D, et al: Dual antiglioma action of metformin: cell cycle arrest and mitochondria-dependent apoptosis. Cell Mol Life Sci 64: 1290-1302, 2007.

8. Zakikhani M, Dowling R, Fantus IG, Sonenberg N and Pollak M: Metformin is an AMP kinase-dependent growth inhibitor for breast cancer cells. Cancer Res 66: 10269-10273, 2006.

9. Kato K, Gong J, Iwama $\mathrm{H}$, et al: The antidiabetic drug metformin inhibits gastric cancer cell proliferation in vitro and in vivo. Mol Cancer Ther 11: 549-560, 2012.

10. Masaki T, Tokuda M, Yoshida S, et al: Comparison study of the expressions of myristoylated alanine-rich $\mathrm{C}$ kinase substrate in hepatocellular carcinoma, liver cirrhosis, chronic hepatitis and normal liver. Int J Oncol 26: 661-671, 2005.

11. Yukimasa S, Masaki T, Yoshida S, et al: Enhanced expression of p46 Shc in the nucleus and p52 Shc in the cytoplasm of human gastric cancer. Int J Oncol 26: 905-911, 2005.

12. Bradford MM: A rapid and sensitive method for the quantitation of microgram quantities of protein utilizing the principle of protein-dye binding. Anal Biochem 72: 248-254, 1976.

13. Laemmli UK: Cleavage of structural proteins during the assembly of the head of bacteriophage T4. Nature 227: 680-685, 1970.

14. Towbin H, Staehelin T and Gordon J: Electrophoretic transfer of proteins from polyacrylamide gels to nitrocellulose sheets: procedure and some applications. Proc Natl Acad Sci USA 76: 4350-4354, 1979

15. Anisimov VN, Berstein LM, Egormin PA, et al: Effect of metformin on life span and on the development of spontaneous mammary tumors in HER-2/neu transgenic mice. Exp Gerontol 40: 685-693, 2005.

16. Masaki T, Shiratori Y, Rengifo W, et al: Cyclins and cyclindependent kinases: comparative study of hepatocellular carcinoma versus cirrhosis. Hepatology 37: 534-543, 2003.

17. Zhuang Y and Miskimins WK: Cell cycle arrest in metformin treated breast cancer cells involves activation of AMPK, downregulation of cyclin D1, and requires p27Kip1 or p21Cip1. J Mol Signal 3: 18, 2008.

18. Vazquez-Martin A,Oliveras-Ferraros C,Cufi S, Martin-Castillo B and Menendez JA: Metformin activates an ataxia telangiectasia mutated (ATM)/Chk2-regulated DNA damage-like response. Cell Cycle 10: 1499-1501, 2011.

19. Liu B, Fan Z, Edgerton SM, et al: Metformin induces unique biological and molecular responses in triple negative breast cancer cells. Cell Cycle 8: 2031-2040, 2009.

20. Wang LW, Li ZS, Zou DW, Jin ZD, Gao J and Xu GM: Metformin induces apoptosis of pancreatic cancer cells. World J Gastroenterol 14: 7192-7198, 2008.

21. Yang YL, Xu KL, Zhou Y, Gao X and Chen LR: Correlation of epidermal growth factor receptor overexpression with increased epidermal growth factor receptor gene copy number in esophageal squamous cell carcinomas. Chin Med J (Engl) 125: 450-454, 2012.

22. Perry JE, Grossmann ME and Tindall DJ: Epidermal growth factor induces cyclin D1 in a human prostate cancer cell line. Prostate 35: 117-124, 1998.

23. Kitadai Y, Onogawa S, Kuwai T, et al: Angiogenic switch occurs during the precancerous stage of human esophageal squamous cell carcinoma. Oncol Rep 11: 315-319, 2004.

24. Zhang Y, Liao JM, Zeng SX and Lu H: p53 downregulates Down syndrome-associated DYRK1A through miR-1246. EMBO Rep 12: 811-817, 2011.

25. Colquhoun AJ, Venier NA, Vandersluis AD, et al: Metformin enhances the antiproliferative and apoptotic effect of bicalutamide in prostate cancer. Prostate Cancer Prostatic Dis: May 22, 2012 (Epub ahead of print). 